\title{
Acceptance of the coronavirus disease- 2019 vaccine among medical students in Uganda
}

\author{
Andrew Marvin Kanyike ${ }^{1 *}$ D, Ronald Olum², Jonathan Kajjimu³, Daniel Ojilong ${ }^{1}$, Gabriel Madut Akech', \\ Dianah Rhoda Nassozi ${ }^{4}$, Drake Agira ${ }^{5}$, Nicholas Kisaakye Wamala ${ }^{6}$, Asaph Asiimwe $^{7}$, Dissan Matovu', \\ Ann Babra Nakimuli ${ }^{9}$, Musilim Lyavala ${ }^{10}$, Patricia Kulwenza ${ }^{10}$, Joshua Kiwumulo ${ }^{11}$ and Felix Bongomin ${ }^{12,13}$
}

\begin{abstract}
Background: COVID-19 is still a major global threat for which vaccination remains the ultimate solution. Uganda reported 40,751 cases and 335 deaths as of 9 April 2021 and started its vaccination program among priority groups like health workers, teachers, those with chronic diseases among others in early March 2021. Unanimous uptake of the COVID-19 vaccine is required to subsequently avert its spread; therefore, we assessed COVID-19 vaccine acceptability, hesitancy, and associated factors among medical students in Uganda.

Methods: This study employed an online descriptive cross-sectional survey among medical students across 10 medical schools in Uganda. A structured questionnaire via Google Form was conveniently sent to eligible participants via WhatsApp. Each medical school had a coordinator who consistently shared the data tool in the WhatsApp groups. Chi-square or Fisher's exact test, and logistic regression were used to assess the association between vaccine acceptability with demographics, COVID-19 risk perception, and vaccine hesitancy.
\end{abstract}

Results: We surveyed 600 medical students, 377 (62.8\%) were male. COVID-19 vaccine acceptability was 37.3\% and vaccine hesitancy $30.7 \%$. Factors associated with vaccine acceptability were being male (adjusted odds ratio $(\mathrm{aOR})=$ $1.9,95 \% \mathrm{Cl} 1.3-2.9, p=0.001)$ and being single $(\mathrm{aOR}=2.1,95 \% \mathrm{Cl} 1.1-3.9, p=0.022)$. Very high $(\mathrm{aOR}=3.5,95 \% \mathrm{Cl} 1.7-$ $6.9, p<0.001$ ) or moderate ( $\mathrm{aOR}=2.2,95 \% \mathrm{Cl} 1.2-4.1, p=0.008)$ perceived risk of getting COVID-19 in the future, receiving any vaccine in the past 5 years (aOR $=1.6,95 \% \mathrm{Cl} 1.1-2.5, p=0.017$ ), and COVID-19 vaccine hesitancy (aOR $0.6,95 \% \mathrm{Cl} 0.4-0.9, p=0.036)$.

Conclusions: This study revealed low levels of acceptance towards the COVID-19 vaccine among medical students, low self-perceived risks of COVID-19, and many had relied on social media that provided them with negative information. This poses an evident risk on the battle towards COVID-19 in the future especially when these future health professions are expected to be influencing decisions of the general public towards the same.

Keywords: COVID-19, Vaccine acceptance, Vaccine hesitancy, Medical students

\footnotetext{
* Correspondence: nyikskam@gmail.com

${ }^{1}$ Faculty of Health Sciences, Busitema University, Mbale, Uganda

Full list of author information is available at the end of the article
}

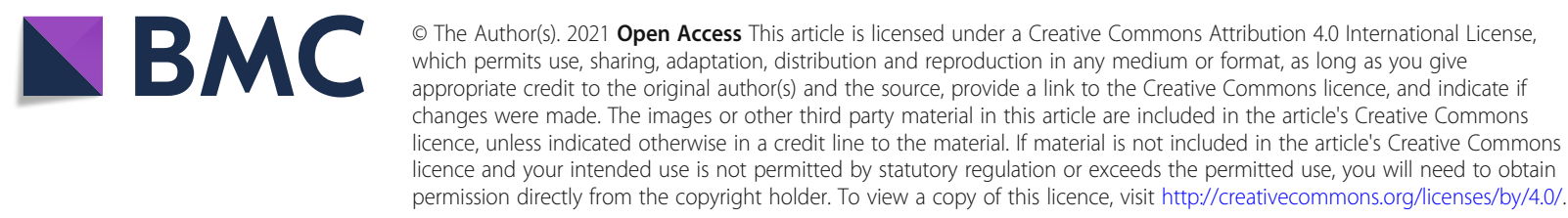




\section{Introduction}

The coronavirus disease-2019 (COVID-19) pandemic, caused by the novel severe acute respiratory syndrome-coronavirus-2 (SARS-CoV-2) continues to create mayhem across the globe. COVID-19 has affected livelihoods and has imposed strains on the health care systems [1]. Over135 million people have been infected with SARS-CoV-2 resulting in over 2.9 million deaths worldwide [2]. The African continent has continuously recorded fewer cases of COVID-19 with about 4.3 million cases and 115,321 deaths [2]. Uganda reported 40,751 cases with 335 deaths as of 9 April 2021 [3].

Various chemotherapeutic and biologic therapies, like hydroxychloroquine, remdesivir, convalescent plasma, and tocilizumab, have been tried to treat COVID-19 patients [4-6] with no conclusive specific curative effect. Different preventive public health measures like lockdowns, hand washing, respiratory hygiene, and social distancing have been employed with little success [7]. Much worse even, attempts to loosen these precautionary behaviors have culminated in the surge of cases in many countries [7]. Leaving room for only an effective vaccine as a long-lasting solution in such a crisis $[8,9]$.

Several vaccine candidates have been developed to date with some approved and others still undergoing clinical trials. Notably, the New York-based PfizerBioNTech, ModernaInc company, and the AstraZeneca/ University of Oxford Vaccines have been approved for emergency use and already rolled out in some countries including Uganda [10]. Although much progress has been made with vaccine development, uncertainty about the public acceptance of COVID-19 vaccination is still an important challenge [9]. The World Health Organization (WHO) asserts that vaccine hesitancy is one of the top ten threats to global health and this is exacerbated by the emerging conspiracies surrounding COVID-19 and its vaccines [11].

Medical students are regarded as an insightful population that is open-minded, educated, and medically informed. They also represent the future health professionals, who are supposed to respond quickly to public health issues [12]. Surprisingly, a study done in the USA reported that nearly one-quarter of the medical students were hesitant to be vaccinated as soon as an approved COVID-19 vaccine becomes available, despite self-perception of elevated risk of exposure to SARS-CoV-2 infection [13]. Furthermore, another study done in Israel reported a high rate of COVID19 vaccine skepticism among medical staff implying that vaccination compliance, even among medically informed individuals, is not automatic [14].

The Ugandan government through the COVAX facility received its first 864,000 doses of the AstraZeneca
Table 1 Demographic characteristics of participants

\begin{tabular}{|c|c|c|}
\hline Demographics & Frequency & $\%$ \\
\hline \multicolumn{3}{|l|}{ Age } \\
\hline$\leq 24$ & 367 & 61.2 \\
\hline$>24$ & 233 & 38.8 \\
\hline \multicolumn{3}{|l|}{ Sex } \\
\hline Male & 377 & 62.8 \\
\hline Female & 223 & 37.2 \\
\hline \multicolumn{3}{|l|}{ Marital status } \\
\hline Single & 521 & 87.1 \\
\hline Married & 74 & 12.4 \\
\hline Separated & 3 & 0.5 \\
\hline \multicolumn{3}{|l|}{ Religion } \\
\hline Anglican & 184 & 30.7 \\
\hline Roman Catholic & 166 & 27.7 \\
\hline Muslim & 102 & 17.0 \\
\hline Pentecostal & 90 & 15.0 \\
\hline Other & 35 & 5.8 \\
\hline SDA & 21 & 3.5 \\
\hline Orthodox & 2 & 0.3 \\
\hline \multicolumn{3}{|l|}{ University of Study } \\
\hline Busitema University & 122 & 20.4 \\
\hline Kampala international University & 102 & 17.1 \\
\hline Makerere University & 89 & 14.9 \\
\hline Kabale University & 71 & 11.9 \\
\hline Islamic University in Uganda & 62 & 10.4 \\
\hline Mbarara University of Science and Technology & 55 & 9.2 \\
\hline Gulu University & 43 & 7.2 \\
\hline King Caesar University & 20 & 3.3 \\
\hline Soroti University & 20 & 3.3 \\
\hline Uganda Christian University & 14 & 2.3 \\
\hline \multicolumn{3}{|l|}{ Year of study } \\
\hline Year 1 & 91 & 15.2 \\
\hline Year 2 & 81 & 13.5 \\
\hline Year 3 & 131 & 21.8 \\
\hline Year 4 & 157 & 26.2 \\
\hline Year 5 & 140 & 23.3 \\
\hline \multicolumn{3}{|l|}{ Academic program } \\
\hline Bachelor of Biomedical laboratory technology & 4 & 0.7 \\
\hline Bachelor of Biomedical sciences & 10 & 1.7 \\
\hline Bachelors of Anaesthesia & 16 & 2.7 \\
\hline Bachelors of Dental Surgery & 11 & 1.8 \\
\hline Bachelors of Medicine and Surgery & 488 & 81.3 \\
\hline Bachelors of Nursing & 58 & 9.7 \\
\hline Bachelors of Pharmacy & 13 & 2.2 \\
\hline
\end{tabular}

SDA Seventh Day Adventists 
vaccine in early March [15]. Subsequently, Uganda rolled out COVID-19 vaccination across the country, starting with priority groups consisting of healthcare workers, security personnel, teachers, humanitarian frontline workers, and patients at higher risk of severe COVID-19 disease among others [15].

In Uganda, medical students form a core part of the health care response team in regional and national referral hospitals making them a vulnerable group [16]. They are also an important force in health education and communication in their various communities. It is therefore imperative to assess the acceptability and attitudes of these students towards the COVID-19 vaccine. To our knowledge, no such study has been done in Uganda, and Africa at large. Therefore, we aimed to assess COVID-19 vaccine acceptability, hesitancy, and associated factors among medical students in Uganda.

\section{Methods}

\section{Study design}

We conducted an online, descriptive, cross-sectional study between Monday 15 March and Sunday 21 March 2021 using a quantitative approach.

\section{Study setting}

The study was carried out in 10 universities in Uganda offering undergraduate medical degrees, namely, Makerere University (Mak), Mbarara University of Science and Technology (MUST), Gulu University (GU), Kampala International University (KIU), Kabale University (KU), Busitema University (BU), Islamic University in Uganda, Soroti University (SU), King Caesar International University, and Uganda Christian University (UCU). Mak, GU, MUST, BU, KU, and SU are public universities, and the remaining universities are private. The combined population size of all these medical schools is about 6000-8000 students.

\section{Study population}

Medical students pursuing the following undergraduate degree programs in these various universities were targeted: Bachelor of Medicine and Bachelor of Surgery (MBChB), Bachelor of Dental Surgery (BDS), Bachelor of Nursing (BNS), Bachelor of Anesthesia (BNA), Bachelor of Pharmacy (BPHARM), Bachelor of Biomedical Laboratory Technology (BLT), and Bachelors of Biomedical Sciences (BBS). MBChB and BDS courses run for 5 years; BNS, BNA, and BPHARM are done for 4 years while BLT and BBS go for 3 years in our sampled universities.

\section{Inclusion and exclusion criteria}

Individuals aged 18 years or older, currently, students in the abovementioned universities who consented to participate, were included and those students who could not access the Internet were excluded.

\section{Sampling procedure and data collection}

During this study, Uganda was in a partial lockdown with schools, universities, and institutions partially opened conducting hybrid physical and Open Distance E-Learning. Therefore, we opted to use WhatsApp Messenger (Facebook Inc) for enrolling potential participants based on our previous experience with conducting studies among medical students [16]. We employed convenience sampling where we identified all the existing WhatsApp groups of medical students in the various universities through a coordinator for each specific university. The Google Form link to the questionnaire was then sent to the potential participants via the identified WhatsApp groups.

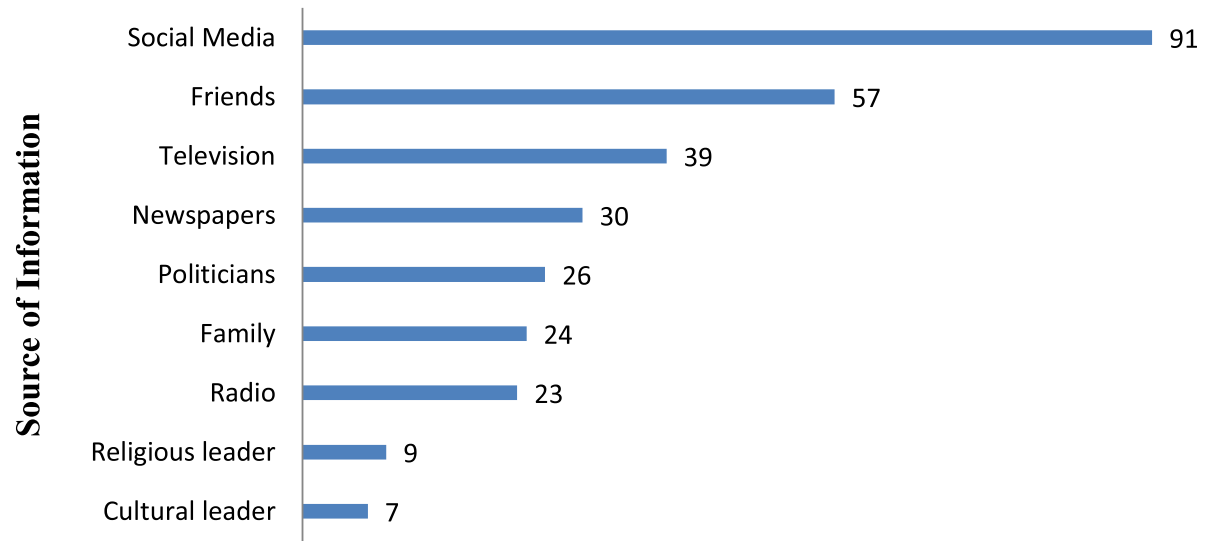

Percentage

Fig. 1 Sources of negative information on the COVID-19 vaccine among medical student 
Table 2 Acceptability of COVID-19 vaccine among medical students in Uganda

\begin{tabular}{lll}
\hline Acceptability of the COVID-19 Vaccine & Frequency & $\%$ \\
\hline Are you aware of a vaccine for COVID-19? & & \\
Yes & 590 & 98.3 \\
No & 10 & 1.7
\end{tabular}

COVID-19 vaccine may be effective in protecting me from COVID19.

$\begin{array}{lll}\text { Strongly agree } & 75 & 12.5 \\ \text { Agree } & 198 & 33.0 \\ \text { Neutral } & 220 & 36.7 \\ \text { Disagree } & 55 & 9.2 \\ \text { Strongly disagree } & 52 & 8.7\end{array}$

Are you willing to get vaccinated with the approved COVID-19 vaccine?

Yes

No

Reasons for accepting $(n=224)$

To protect myself from getting COVID-19.

To protect others from getting COVID-19.

I believe in vaccines and immunization.

To get rid of the virus and end the pandemic.

Health workers' recommendations.

To be able to travel.

It is a social and moral responsibility.

If the vaccine is free of charge.

If it is available to me.

The vaccines are effective.

The vaccines are safe.

Government recommendations.

Job requirement.

I am at high risk of severe disease.

Reason for not accepting the vaccine $(n=376)$

I don't think the vaccine is safe/concerned about side effects

I have heard or read negative information on the vaccine.

I don't think the vaccine is effective

I trust my immunity

I don't think it is needed

Someone else told me that the vaccine is not safe

I don't know where to get good/reliable

information

Fear of needles

Religious reasons

I don't know where to get vaccination

Someone else told me they/their child had a bad reaction
Table 2 Acceptability of COVID-19 vaccine among medical students in Uganda (Continued)

\begin{tabular}{lll}
\hline Acceptability of the COVID-19 Vaccine & Frequency & \% \\
\hline $\begin{array}{l}\text { Had a bad experience or reaction with previous } \\
\text { vaccination }\end{array}$ & 6 & 1.6 \\
$\begin{array}{l}\text { Vaccine development was rushed } \\
\text { Had a bad experience with previous vaccinator/ }\end{array}$ & 6 & 1.6 \\
health clinic & 4.1 \\
$\begin{array}{l}\text { Not possible to leave other work (at home or } \\
\text { Other) }\end{array}$ & 3 & 0.8 \\
Other beliefs/traditional medicine & 2 & 0.5 \\
\hline
\end{tabular}

\section{Data collection tool}

We adapted a validated questionnaire as used by Tamam and colleagues [17] and modified it to suit our study population. The questionnaire was structured into four sections. The first section captured socio-demographic information including age, sex, program of study, university, religion among others. The second section assessed COVID-19 pandemic-related information entailing whether the participant was confirmed to be infected with COVID-19 or thought so, if they knew anyone who was infected and confirmed by laboratory test. It also assessed what they thought was the magnitude of threat COVID-19 posed to them, the entire Uganda, and if they believed to have already acquired immunity against COVID-19. The third section was about acceptance and hesitancy to COVID-19 vaccines where participants were asked if they would take the vaccine when availed and give reason for their answers. It also assessed if participants had been reluctant or refused to take vaccines in the past 5 years. The fourth section assessed the attitude towards the COVID-19 vaccine.

\section{Study variables}

Independent variables were the demographic characteristics including sex, age, education program, religion, residence, education institution, and sources of information on COVID-19 and COVID-19 vaccines and dependent variables were the acceptability, hesitancy, trust, and attitudes towards COVID-19 vaccine.

\section{Data management analysis}

Fully completed questionnaires were extracted from Google Forms and exported to Microsoft Excel 2016 (Microsoft Corporation) for cleaning and coding. The cleaned data was exported to STATA (StataCorp LLC, TX, USA) version 16.0 for analyses. Numerical data was summarized as means (standard deviations) or median (inter-quartile range) for parametric and non-parametric data, respectively. Categorical data was summarized as frequencies and proportions. Associations between independent variables and dependent variables were assessed 
using the chi-square test or Fisher's exact test and logistic regression analysis in STATA 16.0 software. A $P<.05$ was considered statistically significant.

\section{Results}

\section{Socio-demographic characteristics}

A total of 600 medical students completed the survey. The majority were male $(n=377,62.8 \%)$, single $(n=521$, $87.1 \%)$, of Anglican religion ( $n=184,30.7 \%)$, pursing MBChB degree $(n=488,81.3 \%)$, and in their fourth year of study ( $n=157,26.2 \%)$. BU had the highest number of participants $(n=122,20.4 \%)$; meanwhile, the least $(n=14$, $2.3 \%)$ number of participants were from UCU. Table 1 summarizes the socio-demographic characteristics of the participants.

\section{Acceptability of COVID-19 vaccine and associated factors among medical students}

The majority of the participants $(n=376,62.7 \%)$ were not willing to be vaccinated against COVID-19. The most cited reasons for not taking up the vaccine were concerns about safety $(n=242,64.4 \%)$ and having heard or read negative information about the vaccine $(n=201$, $53.5 \%)$. Of those that reported to have heard negative information about COVID-19 vaccine $(n=575,95.8 \%)$, the biggest sources were from social media ( $n=521,90.6 \%)$, and friends $(n=325,56.5 \%)$ (Fig. 1). For the participants willing to take up the COVID-19 vaccine $(n=224$, $37.3 \%)$, the major reasons for acceptance were to protect oneself $(n=191,85.3 \%)$ and others $(n=142,63.4 \%)$ from COVID-19. Close to half $(n=111,49.6 \%)$ of the participants believed in vaccines and immunization. Table 2 summarizes reasons for acceptance and hesitancy of the COVID-19 vaccine.

Of the 224 participants willing to be vaccinated, the majority $(n=84,38 \%)$ were indifferent to the particular vaccine they would take, $34 \%(n=77)$ would wish to take the Pfizer-BioNTech vaccine, and only $19 \%$ the AstraZeneca vaccine (Fig. 2).

On bivariate analysis, sex $(p=0.001)$, belief of getting COVID-19 in the future $(p<0.001)$ or having already had it $(p<0.029)$, perceived risk of COVID-19 to an individual $(p=0.001)$ and Uganda at large $(p<0.001)$, belief on effectiveness of the vaccine $(p<0.001)$, vaccination uptake in the previous five years $(p=0.028)$ and reluctance or hesitancy to vaccination $(p=0.004)$ were significantly associated with acceptability of COVID-19 vaccine (Table 3 ).

On multivariable logistic regression analysis, significant factors for acceptability were being male (adjusted odds ratio $(\mathrm{aOR})=1.9,95 \%$ CI $1.3-2.9, p=0.001)$, being single $(\mathrm{aOR}=2.1,95 \% \mathrm{CI} 1.1-3.9, p=0.022)$, moderate $(\mathrm{aOR}=2.2,95 \% \mathrm{CI} 1.2-4.1, p=0.008)$ or very high $(\mathrm{aOR}=$ $3.5,95 \%$ CI 1.7-6.9, $p<0.001)$ perceived risk of getting COVID-19 in the future, and receiving any vaccine in the past 5 years $(\mathrm{aOR}=1.6,95 \%$ CI $1.1-2.5, p=0.017)$. However, participants who were reluctant or hesitant to get vaccination before $(\mathrm{aOR}=0.6,95 \% \mathrm{CI} 0.4-0.9, p=$ $0.036)$ were less likely to take up the COVID-19 vaccine (Table 4).

\section{Vaccine hesitancy among medical students}

About two third $(66.8 \%, n=401)$ of the participants had not received any vaccine in the past 5 years. However, (30.7\%, $n=184$ ) reported having been hesitant. The most

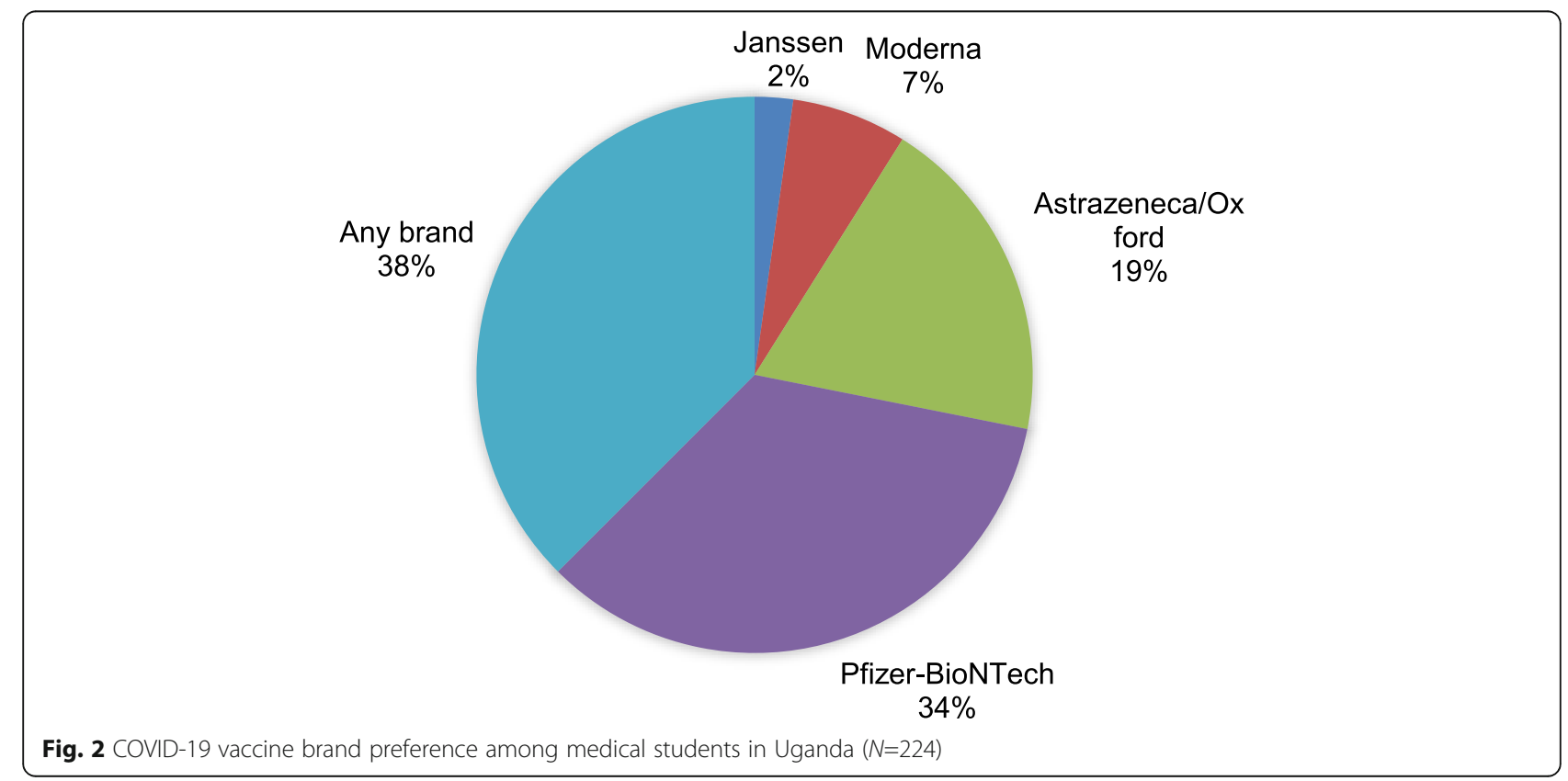


Table 3 Factors associated with acceptability of the COVID-19 vaccine among medical students in Uganda

\begin{tabular}{|c|c|c|c|}
\hline \multirow[t]{2}{*}{ Variables } & \multicolumn{3}{|c|}{ Acceptability } \\
\hline & $\begin{array}{l}\text { No } \\
(N=376)\end{array}$ & $\begin{array}{l}\text { Yes } \\
(N=224)\end{array}$ & $p$-value \\
\hline \multicolumn{4}{|l|}{ Age } \\
\hline$\leq 24$ & $224(61)$ & $143(39)$ & \multirow[t]{2}{*}{0.300} \\
\hline$>24$ & $152(65.2)$ & $81(34.8)$ & \\
\hline \multicolumn{4}{|l|}{ Sex } \\
\hline Female & $159(71.3)$ & $64(28.7)$ & \multirow[t]{2}{*}{0.001} \\
\hline Male & $217(57.6)$ & $160(42.4)$ & \\
\hline \multicolumn{4}{|l|}{ Marital status } \\
\hline Married & $54(73)$ & $20(27)$ & \multirow[t]{3}{*}{0.124} \\
\hline Separated & $2(66.7)$ & $1(33.3)$ & \\
\hline Single & $319(61.2)$ & $202(38.8)$ & \\
\hline \multicolumn{4}{|l|}{ Religion } \\
\hline Anglican & $108(58.7)$ & $76(41.3)$ & \multirow[t]{7}{*}{0.036} \\
\hline Muslim & $60(58.8)$ & $42(41.2)$ & \\
\hline Orthodox & $2(100)$ & $0(0)$ & \\
\hline Other & $21(60)$ & $14(40)$ & \\
\hline Pentecostal & $68(75.6)$ & $22(24.4)$ & \\
\hline Roman Catholic & $108(65.1)$ & $58(34.9)$ & \\
\hline SDA & $9(42.9)$ & $12(57.1)$ & \\
\hline \multicolumn{4}{|l|}{ University of Study } \\
\hline Busitema University & $83(68)$ & $39(32)$ & \multirow[t]{10}{*}{0.443} \\
\hline Gulu University & $25(58.1)$ & $18(41.9)$ & \\
\hline Islamic University & $41(66.1)$ & $21(33.9)$ & \\
\hline Kabale University & $43(60.6)$ & $28(39.4)$ & \\
\hline Kampala International University & $61(59.8)$ & $41(40.2)$ & \\
\hline King Caesar University & $11(55)$ & $9(45)$ & \\
\hline Makerere University & $53(59.6)$ & $36(40.4)$ & \\
\hline Mbarara University of Science and Technology & $33(60)$ & $22(40)$ & \\
\hline Soroti University & $17(85)$ & $3(15)$ & \\
\hline Uganda Christian University & $7(50)$ & $7(50)$ & \\
\hline \multicolumn{4}{|l|}{ Year of study } \\
\hline Year 1 & $66(72.5)$ & $25(27.5)$ & \multirow[t]{5}{*}{0.234} \\
\hline Year 2 & $53(65.4)$ & $28(34.6)$ & \\
\hline Year 3 & $79(60.3)$ & $52(39.7)$ & \\
\hline Year 4 & $92(58.6)$ & $65(41.4)$ & \\
\hline Year 5 & $86(61.4)$ & $54(38.6)$ & \\
\hline \multicolumn{4}{|l|}{ Academic Program } \\
\hline Bachelor of Biomedical laboratory technology & $2(50)$ & $2(50)$ & \multirow[t]{7}{*}{0.339} \\
\hline Bachelor of Biomedical sciences & $3(30)$ & $7(70)$ & \\
\hline Bachelors of Anaesthesia & $9(56.3)$ & $7(43.8)$ & \\
\hline Bachelors of Dental Surgery & $6(54.5)$ & $5(45.5)$ & \\
\hline Bachelors of Medicine and Surgery & $307(62.9)$ & $181(37.1)$ & \\
\hline Bachelors of Nursing & $40(69)$ & $18(31)$ & \\
\hline Bachelors of Pharmacy & $9(69.2)$ & $4(30.8)$ & \\
\hline
\end{tabular}

Table 3 Factors associated with acceptability of the COVID-19 vaccine among medical students in Uganda (Continued)

\begin{tabular}{|c|c|c|c|}
\hline \multirow[t]{2}{*}{ Variables } & \multicolumn{3}{|c|}{ Acceptability } \\
\hline & $\begin{array}{l}\text { No } \\
(N=376)\end{array}$ & $\begin{array}{l}\text { Yes } \\
(N=224)\end{array}$ & $p$-value \\
\hline \multicolumn{4}{|c|}{ How likely do you think you will get COVID-19 in future? } \\
\hline Extremely likely & $13(56.5)$ & $10(43.5)$ & $<0.001$ \\
\hline Moderate & $81(54.7)$ & $67(45.3)$ & \\
\hline Not at all & $122(76.3)$ & $38(23.8)$ & \\
\hline Slightly & $122(66.7)$ & $61(33.3)$ & \\
\hline Very likely & $38(44.2)$ & $48(55.8)$ & \\
\hline \multicolumn{4}{|c|}{ Overall, how worried are you about coronavirus? } \\
\hline Extremely & $18(48.6)$ & $19(51.4)$ & $<0.001$ \\
\hline Not at all & $69(75)$ & $23(25)$ & \\
\hline Not very & $145(70.4)$ & $61(29.6)$ & \\
\hline Somewhat & $106(55.8)$ & $84(44.2)$ & \\
\hline Very & $38(50.7)$ & $37(49.3)$ & \\
\hline \multicolumn{4}{|c|}{ To what extent do you think coronavirus poses a risk to you personally? } \\
\hline Major risk & $71(53.8)$ & $61(46.2)$ & 0.001 \\
\hline Minor risk & $151(71.2)$ & $61(28.8)$ & \\
\hline Moderate risk & $120(56.9)$ & $91(43.1)$ & \\
\hline No risk at all & $34(75.6)$ & $11(24.4)$ & \\
\hline
\end{tabular}

Do you think coronavirus poses a risk to people in Uganda?

\begin{tabular}{|c|c|c|}
\hline Major risk & $113(50.2)$ & $112(49.8)$ \\
\hline Minor risk & 91 (77.1) & $27(22.9)$ \\
\hline Moderate risk & $158(65.8)$ & $82(34.2)$ \\
\hline No risk at all & $14(82.4)$ & $3(17.6)$ \\
\hline
\end{tabular}

Do you know if you have had, or currently have, coronavirus?

$\begin{array}{llll}\text { I have definitely had it } & 30(65.2) & 16(34.8) & 0.029 \\ \text { I have definitely not had it } & 134(65) & 72(35) \\ \text { I think I have probably had it } & 129(67.5) & 62(32.5) \\ \text { I think I have probably not had it } & 83(52.9) & 74(47.1) \\ \text { Have you been tested for coronavirus? } & & & \\ \text { No } & 268(62.5) & 161(37.5) & 0.948 \\ \text { Yes-positive } & 19(65.5) & 10(34.5) \\ \text { Yes-negative } & 89(62.7) & 53(37.3)\end{array}$

Has any of your family members tested for COVID-19?

\begin{tabular}{|c|c|c|}
\hline No & $213(61.7)$ & $132(38.3)$ \\
\hline Yes-positive & $51(65.4)$ & $27(34.6)$ \\
\hline (es-negative & $112(63.3)$ & \\
\hline
\end{tabular}

Has any of your friends tested positive for COVID-19?

$\begin{array}{llll}\text { No } & 156(61.7) & 97(38.3) & 0.729 \\ \text { Yes-positive } & 143(64.7) & 78(35.3) & \\ \text { Yes-negative } & 77(61.1) & 49(38.9) & \\ \text { think I have some immunity to coronavirus } & & & \\ \text { Agree } & 110(59.8) & 74(40.2) & 0.088 \\ \text { Disagree } & 34(55.7) & 27(44.3) & \\ \text { Neutral } & 110(64.3) & 61(35.7) \\ \text { Strongly agree } & 111(69.4) & 49(30.6) \\ \text { Strongly disagree } & 11(45.8) & 13(54.2)\end{array}$


Table 3 Factors associated with acceptability of the COVID-19 vaccine among medical students in Uganda (Continued)

\begin{tabular}{|c|c|c|c|}
\hline \multirow[t]{2}{*}{ Variables } & \multicolumn{3}{|c|}{ Acceptability } \\
\hline & $\begin{array}{l}\text { No } \\
(N=376)\end{array}$ & $\begin{array}{l}\text { Yes } \\
(N=224)\end{array}$ & $p$-value \\
\hline \multicolumn{4}{|c|}{ Have you been vaccinated before in the past 5 years? } \\
\hline No & $137(68.8)$ & $62(31.2)$ & 0.028 \\
\hline Yes & $239(59.6)$ & $162(40.4)$ & \\
\hline \multicolumn{4}{|c|}{ Have you ever been reluctant or hesitate to get a vaccination before? } \\
\hline No & $245(58.9)$ & $171(41.1)$ & 0.004 \\
\hline Yes & $131(71.2)$ & $53(28.8)$ & \\
\hline \multicolumn{4}{|c|}{ COVID-19 vaccine may be effective in protecting me from COVID-19. } \\
\hline Agree & $84(42.4)$ & $114(57.6)$ & $<0.001$ \\
\hline Disagree & $53(96.4)$ & $2(3.6)$ & \\
\hline Neutral & $171(77.7)$ & $49(22.3)$ & \\
\hline Strongly agree & $16(21.3)$ & $59(78.7)$ & \\
\hline Strongly disagree & $52(100)$ & $0(0)$ & \\
\hline \multicolumn{4}{|c|}{$\begin{array}{l}\text { Have you ever received or heard negative information about COVID-19 } \\
\text { vaccination? }\end{array}$} \\
\hline No & $17(68)$ & $8(32)$ & 0.573 \\
\hline Yes & $359(62.4)$ & 216 (37.6) & \\
\hline
\end{tabular}

alluded to reason for vaccination hesitancy was concern about vaccines safety or their side effects $(n=78,19.9 \%)$ (Table 5).

\section{COVID-19 risk perception and testing among medical students}

Among the participants, 188(30.5\%) perceived a slight risk of getting COVID-19, and 206 (34.3\%) were not very worried about the disease. Also, 212 (35.3\%) and 211 (35.2\%) thought that COVID-19 possesses a minor and moderate risk to them, respectively. Of the 171 (28.5\%) participants who tested for COVID-19 before, 29 (4.8\%) reported having tested positive. One hundred eightyfour $(30.7 \%)$ students believed they have acquired immunity against COVID-19 (Table 6).

\section{Discussion}

Vaccine hesitancy has been a domain of concern globally for several decades now and the picture is more contentious with the current COVID-19 vaccination due to the infodemic and conspiracies surrounding the disease [14]. In this study, we set out to find the COVID-19 vaccine acceptability, hesitancy, and associated factors among medical students in Uganda. To our knowledge, this is the first study of its kind in Uganda and the African continent at large to examine acceptance and hesitancy towards the COVID-19 vaccine among health care students.

Firstly, our study reveals that only $37.3 \%$ of Ugandan medical students are willing to take up the COVID-19 vaccine. This acceptance level is slightly higher than reported among Egyptian medical students (35\%) [18]. Acceptance levels are much higher among students from Italy (86.1\%) [12], South Carolina (60.6\%) [1], and nursing students (43.8\%) across seven countries [19]. The most cited reasons for acceptance of the COVID19 vaccine were protecting self and others from COVID-19 similar to a study among Egyptian medical students [18]. This finding is supported by Brewer et al. who reported that anticipated regret for lack of action (i.e., not getting a vaccination and being infected and/ or infecting loved ones) is correlated with a higher likelihood of vaccination [20].This study reveals that males are twice more likely to take up the COVID-19 vaccine than their female counterparts, a finding that has been reported by other studies [19, 21]. Our earlier study among Ugandan medical students showed higher negative attitudes among females towards COVID-19 which further underscores this finding [16].

Secondly, we found that $30.7 \%$ of the medical students were hesitant about the COVID-19 vaccination. Hesitancy towards COVID-19 vaccination among university students has been reported elsewhere. Our findings are much lower than reported among Egyptian medical students (46\%) [18]; however, relatively similar findings were reported among medical students in Malta (30.5\%) [11], slightly higher than hesitancy among medical students from South Carolina (24.3\%) [1], and Michigan (23\%) [13], and way higher than that reported among medical students in Italy (13.9\%) [12] and India (10.6\%) [22].This discrepancy could be explained by the variable impact of COVID19 across the globe with a less severe form of the disease and cases in Africa and Uganda in particular. This could directly affect individuals' risk perception of COVID-19 and undermine their decision to take up the vaccine.

In a multicenter study, Evridiki et al. reported that increased risk perception towards COVID-19 was associated with the likely uptake of the COVID-19 vaccine [19].Indeed our results show that the highest proportion (30.5\%) of students perceived a slight risk of getting COVID-19 in future, and 34.3\% were not worried about the disease and it is surely not surprising that uptake was likely among participants that perceived high risk of getting COVID-19 in the future. The most given reason for hesitancy towards the COVID-19 vaccine in this study was concern about its safety and side effects as similarly reported in various other studies [13, 18, 19, 22].

Medical or health care students are thought to be a medically updated and insightful population that would readily take up the vaccine which is paradoxically unlikely. Health care professionals have also been relied on to influence decisions of the general public who seek 
Table 4 A multivariable logistic regression showing factors associated with acceptability of the COVID-19 vaccine among medical students in Uganda

\begin{tabular}{|c|c|c|c|}
\hline Variables & $\begin{array}{l}\text { Adjusted odds ratio } \\
\text { (aOR) }\end{array}$ & $\begin{array}{l}95 \% \\
\mathrm{Cl}\end{array}$ & $p$-value \\
\hline \multicolumn{4}{|l|}{ Sex } \\
\hline Female & Reference & & \\
\hline Male & 1.9 & $\begin{array}{l}1.3- \\
2.9\end{array}$ & 0.001 \\
\hline
\end{tabular}

\section{Marital status}

Married Reference

Separated

Single

$1.1-$ 3.9

\section{Religion}

$\begin{array}{lccc}\text { Anglican } & \text { Reference } & & \\ \text { Muslim } & 0.9 & 0.5- & 0.61 \\ & & 1.5 & \\ \text { Other } & 1.1 & 0.5- & 0.819 \\ & & 2.5 & \\ \text { Pentecostal } & 0.5 & 0.3- & 0.042 \\ & & 1.0 & \\ \text { Roman Catholic } & 0.8 & 0.5- & 0.294 \\ & & 1.3 & \\ \text { SDA } & 1.6 & 0.6- & 0.356 \\ & & 4.4 & \\ \text { How likely do you think you will get CoviD-19 in future? } & \\ \text { Not at all } & \text { Reference } & & \\ \text { Slightly } & 1.5 & 0.9- & 0.153 \\ & & 2.6 & \\ \text { Moderate } & 2.2 & 1.2- & 0.008 \\ & & 4.1 & \\ \text { Very likely } & 3.5 & 1.7- & <0.001 \\ & & 6.9 & \\ \text { Extremely likely } & 2.7 & 1.0- & 0.059 \\ & & 7.4 & \end{array}$

Overall, how worried are you about coronavirus?

$\begin{array}{llll}\text { Not at all worried } & \text { Reference } & & \\ \text { Somewhat worried } & 1.2 & 0.6- & 0.579 \\ & & 2.6 & \\ \text { Not very worried } & 0.8 & 0.4- & 0.553 \\ & & 1.6 & \\ \text { Very worried } & 1.6 & 0.7- & 0.281 \\ & & 3.9 & \\ \text { Extremely worried } & 1.4 & 0.5- & 0.535 \\ & & 3.7 & \end{array}$

To what extent do you think coronavirus poses a risk to you personally?

$\begin{array}{llll}\text { No risk at all } & \text { Reference } & & \\ \text { Minor risk } & 0.9 & 0.3- & 0.815 \\ & & 2.3 & \\ \text { Moderate risk } & 1.0 & 0.3- & 0.931 \\ & & 2.7 & \end{array}$

Table 4 A multivariable logistic regression showing factors associated with acceptability of the COVID-19 vaccine among medical students in Uganda (Continued)

\begin{tabular}{clll}
\hline Variables & $\begin{array}{l}\text { Adjusted odds ratio } \\
\text { (aOR) }\end{array}$ & $\begin{array}{l}\mathbf{9 5 \%} \\
\mathbf{C l}\end{array}$ & $\boldsymbol{p}$-value \\
\hline Major risk & 0.6 & $0.2-$ & 0.432 \\
& & 1.9 &
\end{tabular}

Do you think coronavirus poses a risk to people in Uganda?

$\begin{array}{llll}\text { No risk at all } & \text { Reference } & & \\ \text { Minor risk } & 1.1 & 0.3- & 0.863 \\ & & 5.0 & \\ \text { Moderate risk } & 1.5 & 0.3- & 0.566 \\ & & 6.8 & \\ \text { Major risk } & 3.0 & 0.7- & 0.157 \\ & & 13.7 & \end{array}$

Do you know if you have had, or currently have, coronavirus?

$\begin{array}{llll}\text { I have definitely not had it } & \text { Reference } & & \\ \text { I think I have probably not } & 0.8 & 0.4- & 0.539 \\ \text { had it } & & 1.7 & \\ \text { I think I have probably had } & 1.5 & 0.7- & 0.333 \\ \text { it } & & 3.3 & \\ \text { I have definitely had it } & 1.0 & 0.5- & 0.948 \\ & & 2.3 & \end{array}$

I think I have some immunity to coronavirus

Strongly disagree Reference

$\begin{array}{llll}\text { Disagree } & 0.8 & 0.3- & 0.706 \\ & & 2.3 & \\ \text { Neutral } & 0.5 & 0.2- & 0.185 \\ & & 1.4 & \\ \text { Agree } & 0.8 & 0.3- & 0.716 \\ & & 2.2 & \\ \text { Strongly agree } & 0.9 & 0.3- & 0.828 \\ & & 2.4 & \end{array}$

Have you been vaccinated before in the past 5 years?

$\begin{array}{llll}\text { No } & \text { Reference } & & \\ \text { Yes } & 1.6 & 1.1- & 0.017 \\ & & 2.5 & \end{array}$

Have you ever been reluctant or hesitate to get a vaccination before?

$\begin{array}{llll}\text { No } & \text { Reference } & & \\ \text { Yes } & 0.6 & 0.4- & 0.036 \\ & & 0.9 & \end{array}$

information from them towards the uptake of vaccines $[23,24]$. Therefore in such a situation where they are hesitant warrants more public campaigns and advocacy engaging, all people irrespective of their medical knowledge background on the safety and importance of this vaccination.

The pandemic has been surrounded by a lot of conspiracies that could have greatly swayed many people into hesitancy. From our study having heard negative information about the vaccine and its side effects ranked high among reasons for hesitancy. Furthermore, social 
Table 5 Vaccine hesitancy among medical students in Uganda

\begin{tabular}{lcc}
\hline Hesitancy & \multicolumn{2}{c}{ Frequency } \\
\hline Have you been vaccinated before in the past $\mathbf{5}$ years? \\
Yes & 199 & 33.2 \\
No & 401 & 66.8
\end{tabular}

Have you ever been reluctant or hesitate to get a vaccination before?

\begin{tabular}{|c|c|c|}
\hline Yes & 184 & 30.7 \\
\hline No & 416 & 69.3 \\
\hline \multicolumn{3}{|l|}{ eason for hesitancy } \\
\hline $\begin{array}{l}\text { Did not think the vaccine was safe/concerned } \\
\text { about side effects }\end{array}$ & 78 & 19.9 \\
\hline Did not think it was needed & 54 & 13.8 \\
\hline Did not think the vaccine was effective & 42 & 10.7 \\
\hline Heard or read negative media & 41 & 10.5 \\
\hline Fear of needles & 35 & 9.0 \\
\hline $\begin{array}{l}\text { Did not know where to get good/reliable } \\
\text { information }\end{array}$ & 34 & 8.7 \\
\hline Did not know where to get vaccination & 31 & 7.9 \\
\hline $\begin{array}{l}\text { Someone else told me that the vaccine was not } \\
\text { safe }\end{array}$ & 27 & 6.9 \\
\hline $\begin{array}{l}\text { Someone else told me they had had a bad } \\
\text { reaction from the vaccine }\end{array}$ & 19 & 4.9 \\
\hline $\begin{array}{l}\text { Had a bad experience with previous vaccinator/ } \\
\text { health clinic }\end{array}$ & 5 & 1.3 \\
\hline $\begin{array}{l}\text { Had a bad experience or reaction with previous } \\
\text { vaccination }\end{array}$ & 5 & 1.3 \\
\hline Religious reasons & 4 & 1.0 \\
\hline Other beliefs/traditional medicine & 4 & 1.0 \\
\hline Fear of fake vaccines & 4 & 1.0 \\
\hline Laziness & 4 & 1.0 \\
\hline Not interested & 2 & 0.5 \\
\hline Already had the disease & 1 & 0.3 \\
\hline Costs & 1 & 0.3 \\
\hline
\end{tabular}

media was reported as the major source of negative information about the COVID-19 vaccine. Indeed, Sallam et al. [21] reported that respondents who did not rely on social media as their source of information were likely to accept the vaccine similar to Saied et al. [18] who showed that the hesitancy group reported social media as their major source of COVID-19 information. It is therefore imperative that medical students are encouraged to rely more on other sources of information with censored information than social media.

\section{Limitations}

One of the limitations in this study was the unequal distribution of respondents from the different medical schools and the relatively low sample size compared to the total number of students in these universities. This
Table 6 COVID-19 risk perception and testing among medical students

\begin{tabular}{lcc}
\hline Perception & Frequency & $\%$ \\
\hline How likely do you think you will get COVID-19 in future? & \\
Extremely likely & 23 & 3.8 \\
Very likely & 86 & 14.3 \\
Moderate & 148 & 24.7 \\
Slightly & 183 & 30.5 \\
Not at all & 160 & 26.7 \\
Overall, how worried are you about coronavirus? & \\
Extremely worried & 37 & 6.2 \\
Very worried & 75 & 12.5 \\
Not very worried & 206 & 34.3 \\
Somewhat worried & 190 & 31.7 \\
Not at all worried & 92 & 15.3
\end{tabular}

To what extent do you think coronavirus poses a risk to you personally?

$\begin{array}{lll}\text { Major risk } & 132 & 22.0 \\ \text { Moderate risk } & 211 & 35.2 \\ \text { Minor risk } & 212 & 35.3 \\ \text { No risk at all } & 45 & 7.5\end{array}$

Do you think coronavirus poses a risk to people in Uganda?

$\begin{array}{lll}\text { Major risk } & 225 & 37.5 \\ \text { Moderate risk } & 240 & 40.0 \\ \text { Minor risk } & 118 & 19.7 \\ \text { No risk at all } & 17 & 2.8\end{array}$

Do you know if you have had, or currently have, coronavirus?

$\begin{array}{lll}\text { I have definitely had it } & 46 & 7.7 \\ \text { I have definitely not had it } & 206 & 34.3 \\ \text { | think I have probably had it } & 191 & 31.8 \\ \text { I think I have probably not had it } & 157 & 26.2\end{array}$

Have you been tested for coronavirus?

$\begin{array}{lll}\text { No } & 429 & 71.5 \\ \text { Yes-positive } & 29 & 4.8 \\ \text { Yes-negative } & 142 & 23.7\end{array}$

Has any of your family members tested for COVID-19?

$\begin{array}{lll}\text { No } & 345 & 57.5 \\ \text { Yes-positive } & 78 & 13.0 \\ \text { Yes-negative } & 177 & 29.5\end{array}$

Has any of your friends tested positive for COVID-19?

$\begin{array}{lll}\text { No } & 253 & 42.2 \\ \text { Yes-positive } & 221 & 36.8 \\ \text { Yes-negative } & 126 & 21.0 \\ \text { think I have some immunity to coronavirus } & \\ \text { Strongly agree } & 160 & 26.7 \\ \text { Agree } & 184 & 30.7 \\ \text { Neutral } & 171 & 28.5 \\ \text { Disagree } & 61 & 10.2 \\ \text { Strongly disagree } & 24 & 4.0\end{array}$


is due to the difference in the total number of students with newer universities having fewer students and the low response to online studies, especially that it was not incentivized. Sampling bias due to convenience sampling used in the study limits the representativeness of the study. Self-selection bias may also have occurred due to some potential respondents not having Internet access and thus not being aware of the existence of the survey.

\section{Strengths of the study}

The study provides results from a large cross-section of students in 10 different universities and variable programs; therefore, the results can be generalized. Sending daily reminders to the eligible participants on the targeted WhatsApp groups lessened possible response bias associated with online surveys.

\section{Future directions/research}

A qualitative research study involving a larger sample size to dig deeper into the sentiments of both medical and non-medical students about the COVID-19 vaccine could provide more precise information for targeted messages towards demystifying and changing the attitude of this group of the population towards COVID-19 vaccination.

\section{Conclusion}

In conclusion, this study has shown high low levels of acceptance towards COVID-19 vaccine among medical students which poses an evident risk on the battle towards the COVID-19 in the future especially when we are seeing third waves in some countries. There is a lot of complacency towards COVID-19 with low perceived risks among medical students in Uganda and the majority has been corrupted by the negative information on social media that has swayed them into hesitating vaccination. Much effort needs to be geared towards encouraging medical students to take up the vaccine and providing information about the safety and effectiveness of these vaccines

\section{Abbreviations \\ COVID-19: Coronavirus disease-2019; SARS-CoV-2: Severe acute respiratory syndrome-coronavirus-2; WHO: World Health Organization; \\ COVAX: Coronavirus disease-2019 Vaccines Global Access; MBChB: Bachelor of Medicine and Bachelor of Surgery; BDS: Bachelor of Dental Surgery; BNS: Bachelor of Nursing Science; BNA: Bachelor of Anesthesia; BPHARM: Bachelor of Pharmacy; BLT: Bachelor of Biomedical Laboratory Technology; BBS: Bachelors of Biomedical Sciences}

\section{Acknowledgements}

The authors would like to acknowledge the following medical students who assisted in data collection: Arindagye Mercy Melody, Sserunkuma Jonathan, Kakande Regan, Tayebwa Ali, Nakayondo Shamirah, Ssemakula Brian, Kunuhira Mark, Lumumba Musah, Asiimwe Anita, Muhumuza Nuel, Shamsudeen Aliu, Katerrega Michael, Ivan Lyagoba, and Wafana Nabwana Brenda. All the medical students who spared their time to make this study possible are highly appreciated.

\section{Authors' contributions}

$\mathrm{AMK}, \mathrm{RO}$, and FB conceptualized and designed the study protocol. AMK, RO, JK (MUST), DO, GMA, DRN, NKW, AS, DM, ABN, ML, PK, DA, and JK (GU) participated in data collection. $\mathrm{RO}$ and $\mathrm{FB}$ analyzed the data. AMK, RO, JK (MUST), DA, and FB drafted the original manuscript. All authors reviewed and approved the final manuscript.

Funding

This research study did not receive any funding.

Availability of data and materials

All data generated or analyzed during the current study is not publicly available due to some individualized information it contains but are available from the corresponding author on reasonable request.

\section{Declarations}

Ethics approval and consent to participate

We sought ethical clearance from the Research Ethics Committee of Cure Children's Hospital of Uganda (CCHU-REC) approval number CCHU-REC/01/ 021. The students were informed that participation in the study was voluntary and electronic informed consent was sought on the initial page of the questionnaire. The ethical principles of involvement of human research subjects as outlined in the Nuremberg Code and the Declaration of Helsinki were strictly adhered to.

Consent for publication

Not applicable

\section{Competing interests}

The authors declare that they have no known competing financial interests or personal relationships that could have appeared to influence the work reported in this paper

\section{Author details}

${ }^{1}$ Faculty of Health Sciences, Busitema University, Mbale, Uganda. ${ }^{2}$ School of Medicine, College of Health Sciences, Makerere University, Kampala, Uganda. ${ }^{3}$ Faculty of Medicine, Mbarara University of Science and Technology, Mbarara, Uganda. ${ }^{4}$ School of Health Sciences, College of Health Sciences, Makerere University, Kampala, Uganda. ${ }^{5}$ School of Medicine, Kabale University, Kabale, Uganda. ${ }^{6}$ Faculty of Clinical Medicine and Dentistry, Kampala International University, Ishaka-, Bushenyi, Uganda. ${ }^{7}$ School of Health Sciences, Soroti University, Soroti, Uganda. ${ }^{8}$ Faculty of Biology, Medicine and Health, King Ceaser University, Kampala, Uganda. ${ }^{9}$ School of Health Sciences, Uganda Christian University, Mukono, Uganda. ${ }^{10}$ Faculty of Medicine, Islamic University in Uganda, Mbale, Uganda. ${ }^{11}$ Faculty of Medicine, Gulu University, Gulu, Uganda. ${ }^{12}$ Department of Medical Microbiology and Immunology, Faculty of Medicine, Gulu University, Gulu, Uganda. ${ }^{13}$ Department of Medicine, College of Health Sciences, Makerere University, Kampala, Uganda.

Received: 14 April 2021 Accepted: 5 May 2021

Published online: 13 May 2021

References

1. Qiao S, Friedman DB, Tam CC, Zeng C, Li X. Vaccine acceptance among college students in South Carolina: Do information sources and trust in information make a difference? medRxiv Prepr Serv Heal Sci. 2020; Available from: http://www.ncbi.nlm.nih.gov/pubmed/33300004\%0A, http://www. pubmedcentral.nih.gov/articlerender.fcgi?artid=PMC7724671.

2. Worldometer . COVID-19 Virus Pandemic Updates 2021. Available from: https://www.worldometers.info/coronavirus/?\%3D\%3D

3. Ministry of Health Uganda. MOH COVID-19 Information Portal [Internet]. 2020 [cited 2020 Jun 7]. Available from: https://covid19.gou.go.ug/?pg= docs\&d=press

4. WHO Solidarity Trial Consortium. Repurposed Antiviral Drugs for Covid-19 — Interim WHO Solidarity Trial Results. N Engl J Med. 2021;384(6):497-511.

5. The RECOVERY Collaborative Group. Dexamethasone in hospitalized patients with Covid-19 - preliminary report. N Engl J Med. 2020:1-11.

6. Agarwal A, Mukherjee A, Kumar G, Chatterjee P, Bhatnagar T, Malhotra P. Convalescent plasma in the management of moderate covid-19 in adults in 
India: Open label phase II multicentre randomised controlled trial (PLACID Trial). BMJ. 2020;371:1-10.

7. Looi MK. Covid-19: Is a second wave hitting Europe? BMJ. 2020;371:4113.

8. Harapan H, Wagner AL, Yufika A, Winardi W, Anwar S, Gan AK, et al. Acceptance of a COVID-19 vaccine in Southeast Asia: a cross-sectional study in Indonesia. Front Public Heal. 2020;8:1-8.

9. Wang J, Jing R, Lai X, Zhang H, Lyu Y, Knoll MD, et al. Acceptance of covid19 vaccination during the covid-19 pandemic in china. Vaccines. 2020;8(3): $1-14$.

10. Pfizer and BioNTech Announce Vaccine Candidate Against COVID-19 Achieved Success in First Interim Analysis from Phase 3 Study | Pfizer [Internet]. [cited 2021 Jan 31]. Available from: https:/www.pfizer.com/news/ press-release/press-release-detail/pfizer-and-biontech-announce-vaccine-ca ndidate-against

11. Grech V , Gauci C. Vaccine hesitancy in the University of Malta Faculties of Health Sciences, Dentistry and Medicine vis-à-vis influenza and novel COVID-19 vaccination. Early Hum Dev. 2020;xxxx:105258. Available from. https://doi.org/10.1016/j.earlhumdev.2020.105258.

12. Barello S, Nania T, Dellafiore F, Graffigna G, Caruso R. 'Vaccine hesitancy' among university students in Italy during the COVID-19 pandemic. Eur J Epidemiol. 2020;35(8):781-3. Available from. https://doi.org/10.1007/s10654020-00670-z.

13. Lucia VC, Kelekar A, Afonso NM. COVID-19 vaccine hesitancy among medical students. J Public Health (Bangkok). 2020;1-5. https://academic.oup. com/jpubhealth/advance-article/doi/10.1093/pubmed/fdaa230/6048931.

14. Dror AA, Eisenbach N, Taiber S, Morozov NG, Mizrachi M, Zigron A, et al. Vaccine hesitancy: the next challenge in the fight against COVID-19. Eur J Epidemiol. 2020;35(8):775-9. Available from. https://doi.org/10.1007/s10654020-00671-y.

15. ReliefWeb. Uganda receives 864,000 doses of COVID-19 vaccines. [Internet]. Available from: https://reliefweb.int/report/uganda/uganda-receives-864000doses-covid-19-vaccines

16. Olum R, Kajjimu J, Kanyike AM, Chekwech G, Wekha G, Nassozi DR, et al. Perspective of medical students on the COVID-19 pandemic: Survey of nine medical schools in Uganda. JMIR Public Heal Surveill. 2020;6(2).

17. Id TE, Abualsamen MM, Almomani BA, Al- NA, Alali FQ. Acceptance and attitudes toward COVID-19 vaccines: A cross-sectional study from Jordan. 2021;(816):1-15. Available from: https://doi.org/10.1371/journal.pone.02 50555

18. Saied SM, Saied EM, Kabbash IA, Abdo SAE. Vaccine hesitancy: Beliefs and barriers associated with COVID-19 vaccination among Egyptian medical students. J Med Virol [Internet]. 2021 Mar 25;19(February):jmv.26910. Available from: https://onlinelibrary.wiley.com/doi/10.1002/jmv.26910

19. Evridiki P, Petros G, Enkeleint AM, Agathi A, Alexandros A, Evanthia A, et al. Factors influencing nursing students' intention to accept COVID-19 vaccination - A pooled analysis of seven countries. medRxiv Prepr Serv Heal Sci. 2021. https://doi.org/10.1101/2021.01.22.21250321.

20. Noel T. B, Jessica T. D, Melissa B. G. Anticipated regret and health behavior: a meta-analysis. HHS Public Access. 2017;35(11):1264-1275.

21. Sallam M, Dababseh D, Eid H, Al-Mahzoum K, Al-Haidar A, Taim D, et al. High Rates of COVID-19 Vaccine Hesitancy and Its Association with Conspiracy Beliefs: A Study in Jordan and Kuwait among Other Arab Countries. Vaccines [Internet]. 2021;9(1):42. Available from: https://www. mdpi.com/2076-393X/9/1/42

22. Jyoti J, Suman S, Akhil DG, Manoj KG, Pankaj B, Pankaja RR. COVID-19 vaccine hesitancy among undergraduate medical students: results from a nationwide survey in India. medRxiv Prepr Serv Heal Sci. 2021. https://doi. org/10.1101/2021.03.12.21253444.

23. Kelekar AK, Lucia VC, Afonso NM, Mascarenhas AK. COVID-19 vaccine acceptance and hesitancy among dental and medical students. J Am Dent Assoc. 2021; Available from. https://doi.org/10.1016/j.adaj.2021.03.006.

24. Nzaji KM, Ngombe KL, Mwamba NG, Ndala BDB, Miema MJ, Lungoyo LC, et al. Acceptability of Vaccination Against COVID-19 Among Healthcare Workers in the Democratic Republic of the Congo. Pragmatic Obs Res [Internet]. 2020;11:103-9. Available from: https://www.dovepress.com/a cceptability-of-vaccination-against-covid-19-among-healthcare-workers-peerreviewed-article-POR.

\section{Publisher's Note}

Springer Nature remains neutral with regard to jurisdictional claims in published maps and institutional affiliations.

\section{Ready to submit your research? Choose BMC and benefit from}

- fast, convenient online submission

- thorough peer review by experienced researchers in your field

- rapid publication on acceptance

- support for research data, including large and complex data types

- gold Open Access which fosters wider collaboration and increased citations

- maximum visibility for your research: over $100 \mathrm{M}$ website views per year

At BMC, research is always in progress.

Learn more biomedcentral.com/submissions 